\title{
Selective Determination of Trinitrotoluene Based on Energy Transfer between Carbon Dots and Gold Nanoparticles
}

\author{
Yones Mosaei Oskoei, ${ }^{*}$ Hassan FatTahi, $*$ Javad Hassanzadeh, ${ }^{* \dagger}$ and Ali Mousavi AzaR*** \\ *North-West Institute of Science and Technology, Malek Ashtar University of Technology, Urmia 5713616864, \\ Iran \\ **Department of Chemistry, Malek Ashtar University of Technology, Shahin Shahr, Iran
}

\begin{abstract}
A fluorescence resonance energy transfer (FRET) system between carbon dots (C-dots) and amine-capped gold nanoparticles (AuNPs) was developed for the selective determination of 2,4,6-trinitrotoluene (TNT). C-dots have an intrinsic florescence emission depending on their exciting wavelength. In the presence of AuNPs, C-dots adsorb on the $\mathrm{Au}$ surfaces, and NPs treat as energy acceptor, which can receive light emitted by C-dots, leading to decrease the fluorescence intensity of C-dots. Furthermore, it is observed that nitroaromatic compounds, especially TNT, could restore this fluorescence due to selective interaction with AuNPs via amine groups, and so releasing the C-dots. Based on this effect, a sensitive and selective fluorescence turn-on probe was designed for the determination of TNT. Some important factors including AuNPs and C-dot concentrations and media $\mathrm{pH}$, which would affect the efficiency of the probe, were optimized. Under the optimum experimental conditions, good linear relationships in the range of $7-250 \mathrm{nmol} \mathrm{L}^{-1} \mathrm{TNT}^{-}$ with the detection limit of $2.2 \mathrm{nmol} \mathrm{\textrm {L } ^ { - 1 }}$ were obtained. The proposed method was satisfactorily applied to the determination of TNT in the environmental water samples. Compared with previous reports, the developed method has relatively high sensitivity, short analysis time, low cost and ease of operation.
\end{abstract}

Keywords Trinitrotoluene, fluorescence, carbon dots, gold nanoparticles, energy transfer

(Received May 29, 2015; Accepted September 7, 2015; Published February 10, 2016)

\section{Introduction}

Nitroaromatic compounds (NAs), which are well known high explosives, have toxic and serious environmental problems. ${ }^{1,2}$ They leave behind wastes that are dangerously polluting the environment and can move into surface and ground water, and incorporate into the food chain. 2,4,6-Trinitrotoluene (TNT), as a widely used explosive, is a toxic compound that can cause skin irritation, anemia, abnormal liver functions and adversely affects male fertility when it is ingested or inhaled. ${ }^{2,3}$ The US Environmental Protection Agency (EPA) has set a limit of $2 \mu \mathrm{g} \mathrm{L}^{-1}$ for TNT in drinking water.,5 But, its concentrations in soil or ground water on the sites where TNT is manufactured, stored, or used can reach levels exceeding $500 \mu \mathrm{g} \mathrm{L}^{-1}$.3,4 Therefore, quick and reliable techniques for the detection of high explosives are necessary for the protection of lives and property, environmental remediation, minefield restoration, forensic analysis, and national security. ${ }^{1,6}$ The common analytical procedures available for the determination of nitroaromatics are: chromatography-mass spectrometry, ${ }^{7,8}$ Raman spectroscopy, ${ }^{9}$ luminescence, ${ }^{2,4,10}$ spectrophotometry, ${ }^{11,12}$ ion mobility spectrometry, ${ }^{13}$ electrochemical methods, ${ }^{14}$ and other various spectroscopic methods. ${ }^{15-18}$ Most of these procedures are tedious and time consuming and need trained personnel, expensive instruments and an extensive sample pretreatment. ${ }^{19}$

$\dagger$ To whom correspondence should be addressed.

E-mail: Javadhassanzadeh63@gmail.com
In the meantime, fluorescence has attracted much attention because of its high sensitivity and simplicity. Trace analysis involving fluorescent dyes has been frequently applied for the determination of explosives. ${ }^{4,10,20}$ On the other hand, nanoparticle-based methods have been recently reported that exhibit a high sensitivity and good selectivity towards the nitroaromatics. Nitroaromatics can interact with certain modified nanoparticles by selective interaction and affect their activities. ${ }^{6,21-32}$ Dasary has exploited Meisenheimer complex formation between TNT and cysteine for its determination. Aggregation of cysteine-capped gold nanoparticles (AuNPs) in the presence of TNT cause color change of the AuNPs suspension. ${ }^{23}$ Ultrasensitive optical detection of trinitrotoluene by ethylenediamine-capped gold nanoparticles has been reported. ${ }^{25}$ Various quantum dots (QDs) capped with amine groups have been applied to the facile and sensitive detection of TNT through fluorescence resonance energy transfer. ${ }^{28,29}$ Also, amine-capped carbon dots have been applied as a nanosensor for the detection of explosives in aqueous solution. ${ }^{32}$

Since the first report of luminescent carbon nanodots (C-dots), ${ }^{33}$ they have attracted much attention. ${ }^{34-37}$ This is because of promising advantages of $\mathrm{C}$-dots, such as tunable luminescence emission, high stability against photobleaching and blinking, biocompatibility, small size, low molecular weight and toxicity. ${ }^{35,37}$

In this paper, a "turn-on" fluorescence sensor for TNT was developed based on its effect on energy transfer efficiency between $\mathrm{C}$-dots and gold nanoparticles. AuNPs quench the fluorescence of C-dots, and interaction of TNT with amine 

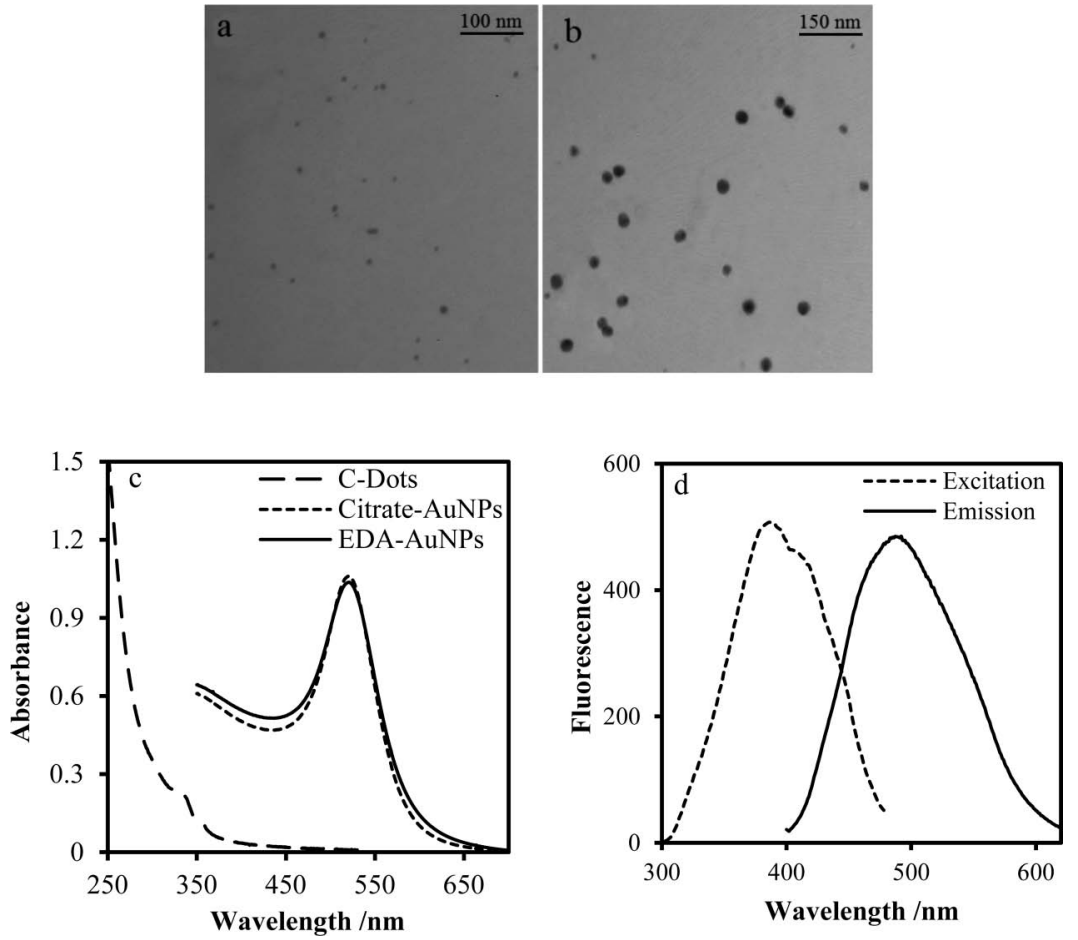

Fig. 1 (a, b) TEM images of (a) C-dots (b) and EDA-AuNPs; (c) absorption spectra of synthesized C-dots and AuNPs; (d) excitation and emission spectra of C-dots.

groups on the surface of AuNPs leads to deactivation of NPs and restoration of the $\mathrm{C}$-dots fluorescence. This method showed good improvements in environmental protection, selectivity and sensitivity, and was satisfactorily used for the determination of TNT in the environmental samples.

\section{Experimental}

\section{Apparatus and chemicals}

Fluorescence spectra and intensities were obtained on a Shimadzu RF-5301 spectrofluorometer (Shimadzu, Tokyo, Japan). Ultraviolet-visible (UV-vis) spectra were recorded on a Shimadzu UV-1800 spectrophotometer. The proper synthesis of AuNPs and C-dots were confirmed through transmission electron microscopy (TEM, Leo 906, Zeiss, Germany).

Chloroauric acid $\left(\mathrm{HAuCl}_{4}\right)$ was purchased from Alfa Aesar (Karlsruhe, Germany). Other reagents were acquired from Merck (Darmstadt, Germany). 2,4,6-Trinitrophenole (TNP) $(98 \%)$ and 2-nitrotoluene (2NT) $(99 \%)$ were purchased from Aldrich. 2,4-Dinitrotoluene (DNT) (99\%) was purchased from Merck, and TNT was provided by the Iranian defense industry. All reagents were of analytical grade and used without further purification. All solutions were prepared by deionized water. Stock solutions of NAs were prepared in acetonitrile and kept at $4^{\circ} \mathrm{C}$.

\section{Preparation of carbon dots and amine-capped AuNPs}

High quantum yield $\mathrm{C}$-dots were synthesized by the Lin group method, ${ }^{38}$ with some modifications. Briefly, $15 \mathrm{~mL}$ of glycerin was mixed with $1.0 \mathrm{~g}$ of poly(ethylene glycol) 1000 (as a passivation agent) and $1.0 \mathrm{~g}$ of citric acid monohydrate (as a carbon source). The mixture was heated to $170^{\circ} \mathrm{C}$ in an oil bath for $30 \mathrm{~min}$ and then was naturally cooled to room temperature.

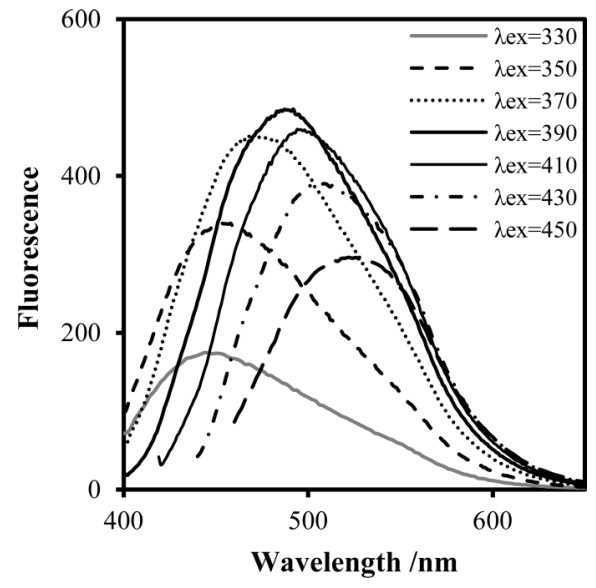

Fig. 2 Emission spectra of C-dots excited in the different wavelengths.

Then, acetone was added into the reaction, and the precipitation was centrifuged. The product was dialyzed against water (dialysis membrane with molecular weight cut-off $=2000 \mathrm{Da}$ ) for 2 days to remove small molecules. Using this method, the highest mass yield of $\mathrm{C}$-dots can reach $62.9 \%$ and the concentration of the C-dots in final $50-\mathrm{mL}$ solution was calculated as $0.57 \mathrm{~mol} \mathrm{~L}^{-1}$, according to the concentration of carbon atoms in the carbon source (moles of $\mathrm{C}$ atoms generated from $1.0 \mathrm{~g}$ citric acid per final volume). TEM images (Fig. 1a) show that the particles of C-dots are almost spherical and monodisperse with average sizes about $6.6 \pm 1.1 \mathrm{~nm}$, which was determined by measuring the diameters of $\sim 150$ particles.

AuNPs were synthesized by simple chemical reduction of 

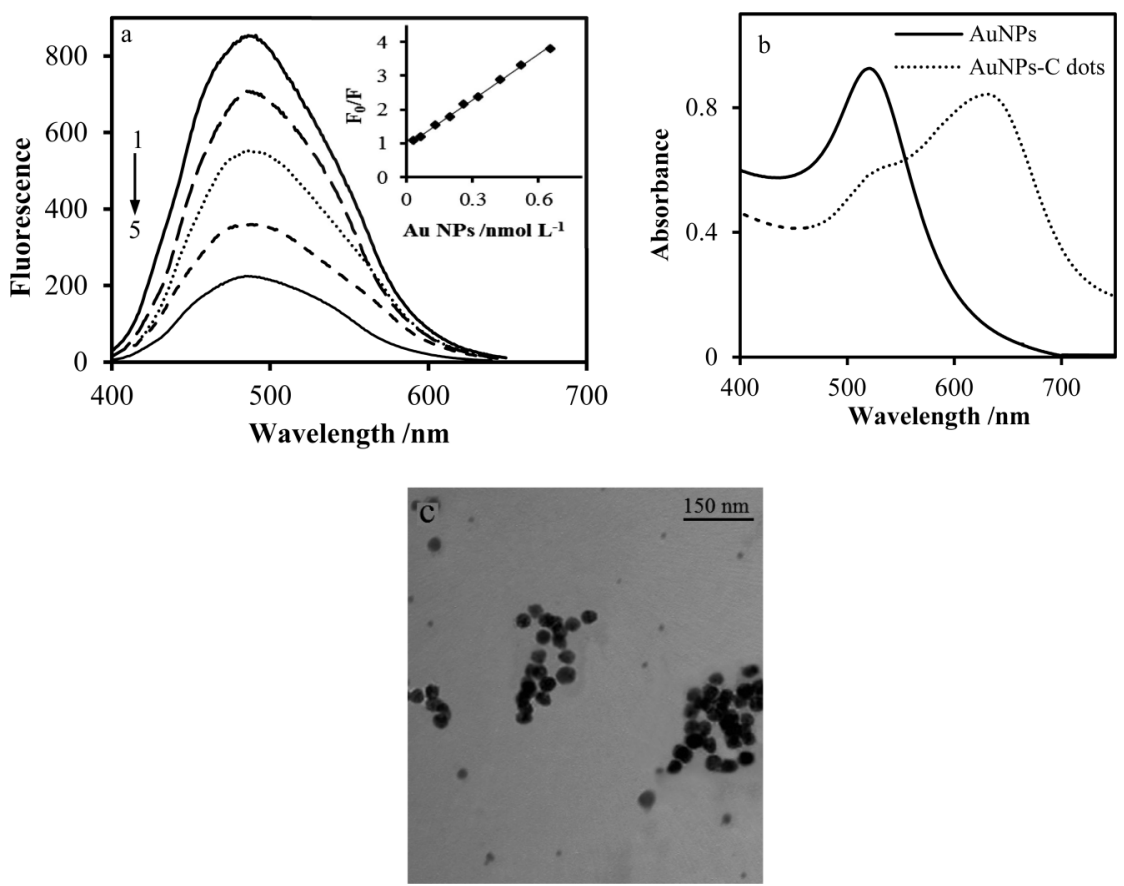

Fig. 3 (a) Fluorescence spectra of $\mathrm{C}$-dots in the presence of various concentrations of AuNPs at the optimum conditions and (inset) the corresponding Stern-Volmer graph (1-5: 0, 0.065, 0.13, 0.33, $0.65 \mathrm{nmol} \mathrm{L}^{-1}$, respectively); (b) absorption spectra of AuNPs in the presence and absence of C-dots; (c) TEM image of EDA-AuNPs in the presence of C-dots.

$\mathrm{HAuCl}_{4}$ with sodium citrate. ${ }^{39}$ Briefly, $100 \mathrm{~mL}$ of a $\mathrm{HAuCl}_{4}$ $\left(2.5 \times 10^{-4} \mathrm{~mol} \mathrm{~L}^{-1}\right)$ solution was heated to boiling point. While stirring vigorously, $5 \mathrm{~mL}$ of $1 \%$ trisodium citrate solution was added rapidly. The solution was maintained at boiling point until a red color was evident. The heating source was then removed and the solution was continuously stirred for $2 \mathrm{~min}$ The concentrations of these NPs were also calculated to be $9.8 \times 10^{-10} \mathrm{~mol} \mathrm{~L}^{-1}$ using the extinction coefficients. ${ }^{39}$ Modification of the prepared AuNPs surface with 1,2-ethylenediamine (EDA) was done according to the Liu procedure. ${ }^{25}$ A 4:1 volume ratio of freshly prepared NPs and EDA $\left(1 \times 10^{-6} \mathrm{~mol} \mathrm{~L}^{-1}\right)$ were mixed by stirring for $12 \mathrm{~h}$ and then excess EDA was removed by centrifugation at $5000 \mathrm{rpm}$ for 15 min. TEM images (Fig. 1b) indicated that average diameters of the synthesized gold NPs were about $22 \pm 1.8 \mathrm{~nm}$ (by measuring the diameters of $\sim 150$ particles).

\section{General procedure for fluorescence detection of TNT}

Fluorescence determinations of TNT were performed as follows: $2000 \mu \mathrm{L}$ amine-capped AuNPs $\left(\sim 1 \mathrm{nmol} \mathrm{L}^{-1}\right), 500 \mu \mathrm{L}$ of synthesized C-dot solution $\left(0.19 \mathrm{~mol} \mathrm{~L}^{-1}\right), \quad 500 \mu \mathrm{L}$ $0.05 \mathrm{~mol} \mathrm{~L}^{-1}(\mathrm{pH}$ 8.0) Tris(hydroxymethyl)aminomethane (Tris) buffer solution and various amounts of TNT standard or sample solution were added to a 5-mL volumetric flask. Then corresponding fluorescence intensity (at $488 \mathrm{~nm}$ ) were recorded with an excitation at $390 \mathrm{~nm}$.

\section{Results and Discussion}

\section{AuNPs and C-dots interaction}

Synthesis of amine-capped AuNPs is very fast, simple and reproducible. Absorption spectra of AuNPs before and after the modification with EDA are shown in Fig. 1c. EDA could be adsorbed on the surface of citrate-gold NPs through its protonated amino group and electrostatic affinity of citrate carboxyl groups. The obtained NPs was stable for several weeks. Absorption spectra presents a maximum wavelength at $518 \mathrm{~nm}$ for both citrate and amine-capped AuNPs, indicating that EDA cannot cause aggregation of the AuNPs in concentration below $1 \mu \mathrm{mol} \mathrm{L}{ }^{-1} .{ }^{25}$ TEM image of the obtained NPs confirm it (Fig. 1b).

Figures 1c and 1d show the UV-vis absorption and fluorescence spectra of the C-dots. The synthesized C-dots have a broad absorption peak at $330 \mathrm{~nm}$ and a strong emission peak at 488 $\mathrm{nm}$ (excited at $390 \mathrm{~nm}$ ), dependent on the excitation wavelength. The quantum yield of C-dots is $17.4 \%$ (determined with quinine sulfate as a reference). The fluorescence of C-dots strongly depends on the excitation wavelength $\left(\lambda_{\mathrm{ex}}\right)$. The emission peak gradually red shifts with increasing the $\lambda_{\text {ex }}$ (Fig. 2).

AuNPs have a high excitation coefficient and a broad absorption spectrum that is overlapped with the emission of C-dots. Also, AuNPs have a good quenching efficiency, extending the effective energy transfer distance up to $20 \mathrm{~nm} .{ }^{40}$ As C-dots were added into the AuNPs solution, C-dots can be adsorbed on NPs. As a result, the fluorescence of C-dots can be quenched through fluorescence resonance energy transfer (FRET) in a few seconds (Fig. 3a). Absorption spectra (Fig. 3b) and TEM image (Fig. 3c) confirm the aggregation of the AuNPs. There are plenty of amine groups on the surface of modified nanoparticles and carboxylic groups on the surface of C-dots. So, the possible electrostatic interaction between these two structures can be considered as the reason for AuNPs aggregation. Quenching effect of AuNPs on the C-dots fluorescence was proportional to the concentration of AuNPs (inset of Fig. 3a) and follow the Stern-Volmer equation in the range of $0.03-0.6 \mathrm{nmol} \mathrm{L}^{-1}$ : 

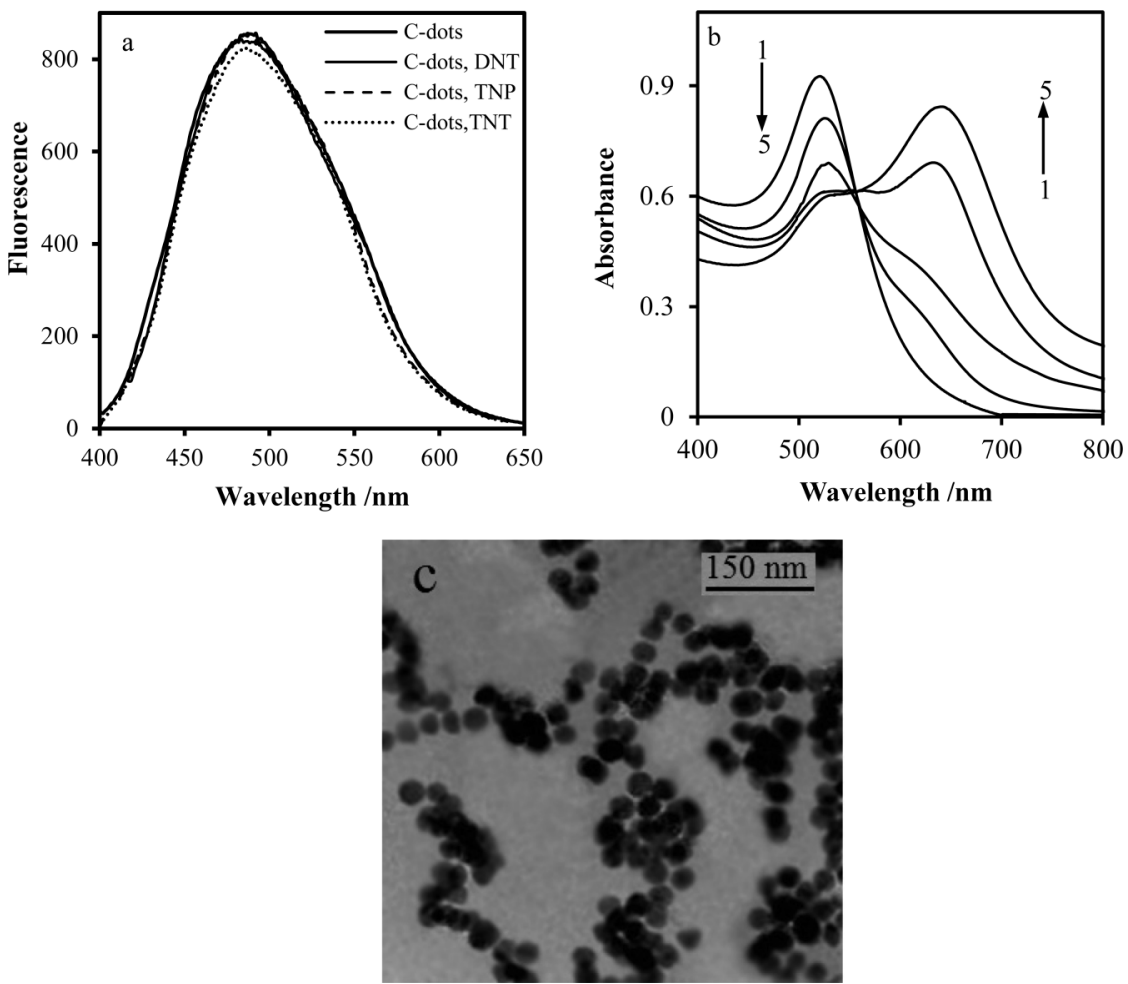

Fig. 4 (a) Fluorescence spectra of C-dots in the presence of various NAs; (b) absorption spectra of EDA capped-AuNPs in the presence of various concentrations of TNT $\left(1-5: 0,0.8,1.5,3,5 \mu \mathrm{mol} \mathrm{L}^{-1}\right.$, respectively); (c) TEM image of EDA-AuNPs after addition of TNT.
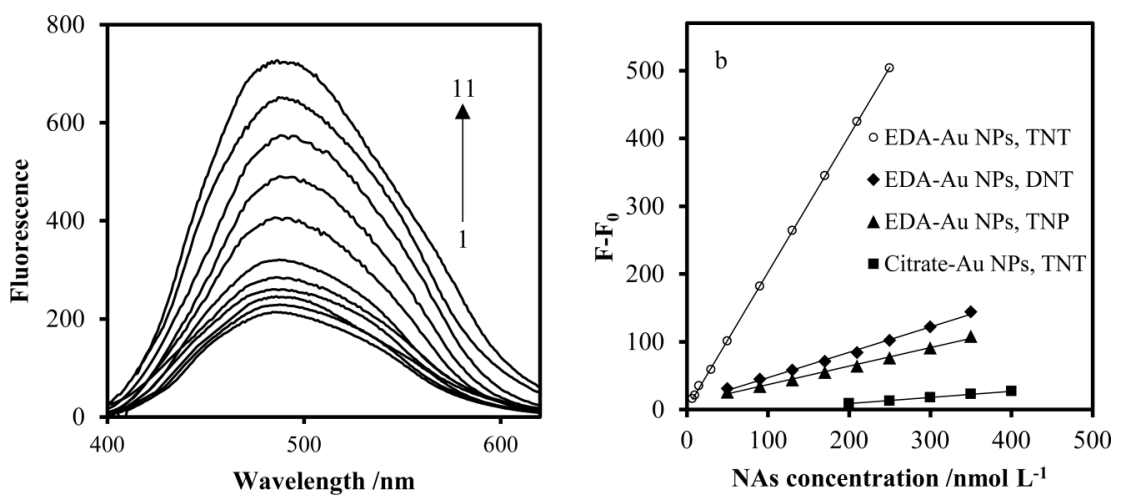

Fig. 5 (a) Fluorescence spectra of C-dots-AuNPs in the presence of various concentrations (1 - 11: 0 , $7,10,15,30,50,90,130,170,210$ and $250 \mathrm{nmol} \mathrm{L}^{-1}$ ) of TNT at the optimum conditions; (b) calibration graph of developed method for various NAs.

$$
F_{0} / F=2[\text { AuNPs }]+0.985(R=0.9948),
$$

where $F_{0} / F$ are the fluorescence intensity ratio of $\mathrm{C}$-dot in the absence $\left(F_{0}\right)$ and presence $(F)$ of AuNPs. [AuNPs] is the concentration of AuNPs in $\mathrm{nmol} \mathrm{L} \mathrm{L}^{-1}$. The quenching constant $\left(K_{\mathrm{SV}}\right)$ was obtained as $2 \times 10^{9} \mathrm{~L} \mathrm{~mol}^{-1}$. On the other hand, the quenching of the fluorescence of C-dots by AuNPs occured in a few seconds and then remained constant.

\section{Interaction of TNT with C-dot and AuNP aggregates}

C-dots show strong fluorescence at $488 \mathrm{~nm}$ (excited at $390 \mathrm{~nm}$ ), that is significantly decreased by AuNPs, due to the FRET process. Addition of NAs restore the quenched fluorescence due to the reduction of the FRET effect. NAs cause negligible effect on the fluorescence of C-dots (Fig. 4a). The developed fluorescence sensor is based on the selective interaction between the NAs and amine groups on the surface of AuNPs. The amine groups on the AuNPs surface acts as the recognition receptors of NAs and a strong molecular interaction occurs between the electron-rich amino groups and electron deficient NAs. This interaction has been used in many methods for quantification purposes. ${ }^{12,22,25,28,29}$

Figure $4 \mathrm{~b}$ shows the UV-vis absorption spectra of aminocapped AuNPs solution in the absence and presence of TNT. Absorption peak of AuNPs in $518 \mathrm{~nm}$ was broadened and shifted to high wavelengths in the presence of TNT. Also, 
the color of AuNPs solution was transferred to blue due to their aggregation in the presence of TNT, which can be clearly observed from TEM image of AuNPs (Fig. 4c). A very weak interaction of TNT with citrate-AuNPs was observed (Fig. S1, Supporting Information). NAs molecules act as BronstedLowrey acid in front of EDA, ${ }^{25}$ and the anion-cation pair of NAs and $\mathrm{NH}_{3}{ }^{+}-\mathrm{R}$ formed on the surface of AuNPs. The huge surface to volume ratio of AuNPs enhance the adsorption affinity to NAs. In result, C-dots can release from NPs and quenching effect on the fluorescence of C-dots is eliminated. Figure 5a shows the evaluation of $\mathrm{C}$-dots fluorescence with the increasing concentrations of TNT. A schematic picture of the sensor system is shown in Scheme 1.

\section{Optimization}

NAs as a Lewis acid, can be deprotonated by amines, as Lewis base, to form an anion. The anion-cation pair $\left(\mathrm{NAs}-\mathrm{RNH}_{3}{ }^{+}\right)$can be decomposed in acidic media. So, the $\mathrm{pH}$ value is the important parameter. Therefore, effect of $\mathrm{pH}$ was investigated on the estabilished fluorescent sensor. As can be seen in Fig. S2a (Supporting Information), mild alkaline media improve the sensor response because amine-NAs reactions take place via amine unpaired electrons, and high pHs inhibit protonation of amines. The maximum increase, $F-F_{0}$, in the fluorescence intensity was obtained in $\mathrm{pH} 8\left(F, F_{0}\right.$ represent the fluorescence intensity in the presence and absence of NAs, respectively).

Type and concentration of buffer to stabilize $\mathrm{pH}$ value were investigated. Several buffer (including Tris, phosphate, borate and ammonium acetate) with different concentrations were tested. The maximum response was obtained for $0.005 \mathrm{~mol} \mathrm{~L}^{-1}$ Tris (Fig. S2b, Supporting Information). Other buffers caused a quenching effect on the fluorescence emission of C-dots.

Effect of the concentration of AuNPs on the signals of NAs was investigated, too (Fig. S2c, Supporting Information). The fluorescence efficiency, $F-F_{0}$, gets better with increasing the AuNPs concentration. But, at levels above $0.4 \mathrm{nmol} \mathrm{L}^{-1}$ AuNPs, it decreased, probably because of an excess amount of AuNPs, which are not protected by NAs sufficiently. Thus, C-dots have more opportunities to come is close contact with the AuNPs.

The effect of EDA/AuNPs was investigated on the fluorescence response for NAs (Fig. S2d, Supporting Information) by

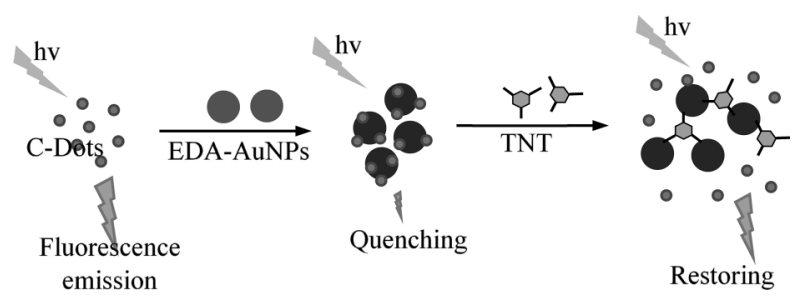

Scheme 1 Schematic picture of the developed sensor system. changing the concentration of EDA between $0-0.8 \mu \mathrm{mol} \mathrm{L} \mathrm{L}^{-1}$, while AuNPs concentration was constant. EDA concentrations higher than $1 \mu \mathrm{mol} \mathrm{L}-1$ caused AuNPs aggregation. As can be seen in Fig. S2d (Supporting Information), the fluorescence restoring effect by NAs increased with increasing EDA up to $0.2 \mu \mathrm{mol} \mathrm{L}^{-1}$ which corresponds to an EDA (solution of $\left.1 \mu \mathrm{mol} \mathrm{L}{ }^{-1}\right) / A u N P s\left(1 \mathrm{nmol} \mathrm{L}^{-1}\right)$ ratio of 1:4 in modification process. Higher amounts of EDA caused lower increasing effect of NAs in fluorescence intensity, and so upper detection limits were obtained.

Finally, effect of the concentration of C-dots was studied (Fig. S2e, Supporting Information). The response to NAs improved by increasing the $\mathrm{C}$-dots concentration. But, at concentration levels above $0.019 \mathrm{~mol} \mathrm{~L}^{-1} \mathrm{C}$-dots, it lessened. This was because additional amounts of C-dots that do not interact with AuNPs and increase initial fluorescence emission in the absence of NAs.

Furthermore, the experiments showed that the addition order of reagents did not have a sensible effect on the fluorescence intensity. All experiments were done by addition of TNT on the C-dots-AuNPs solution.

\section{Application and selectivity}

Figure 5 shows the response of the TNT sensor using aminecapped AuNPs and calibration curves for the tested NAs. As can be seen, TNT exhibits higher increasing efficiency than other analytes. TNT is the strongest acid between NAs, and so a stronger acid-base pairing interaction occurs between TNP and amino groups. In contrast, DNT and TNP are weaker Lewis acids and so, weakly interact with amino groups, and leads to the low restoring efficiency (Fig. 5b). 2NT and NB have no effect because of their very weak acidic properties. The order of increasing effect for experimented analytes is: TNT $>$ DNT $>$ TNP. Table 1 shows the comparison between figure of merits for the determination of TNT, DNT and TNP by developed system. Also, increasing effect of TNT in the presence of amine capped NPs was much better than Citrate-NPs (Fig. 5b and Table 1). The reason is higher affinity of amine-capped NPs to TNT, which leads to the enhanced restoring effect of TNT and improving the measurements sensitivity. Based on this effect, a sensitive method can be proposed for the determination of TNT. Comparison between the proposed technique with some other reported NP-based analytical methods for the TNT quantification is shown in Table 2. As can be seen, the analytical characteristics of this method are better than or comparable with those of other methods. It is rapid and does not require a response time.

In addition, our system is an indirect FRET arrangement based on amine capped AuNPs and unfunctionalized luminescent $\mathrm{C}$-dots, and the emission of the system is not influenced by media compounds in real samples (both with and without TNT). This system was practical compared with direct determination by using amine rich C-dots, in the absence of AuNPs. The direct system was easily affected by interference in real samples,

Table 1 Obtained figure of merits for the determination of NAs by developed method in the same condition

\begin{tabular}{lcccc}
\hline \multirow{2}{*}{ Applied NPs and NAs } & \multicolumn{3}{c}{ EDA capped-AuNPs } & Citrate- AuNPs \\
\cline { 2 - 4 } \cline { 2 - 4 } & TNT & TNP & DNT & TNT \\
\hline Regression equation & $\Delta F=2.014 C+1.42$ & $\Delta F=0.37 C+11.3$ & $\Delta F=0.27 C+10.3$ & $\Delta F=0.89 C+8.50$ \\
Dynamic range/nmol L & $7-250$ & $50-350$ & $50-350$ & $200-400$ \\
LOD/nmol L & 2.2 & 12.1 & 16.5 & 53.5 \\
$R^{2}$ & 0.9999 & 0.9958 & 0.9954 & 0.9999 \\
\hline
\end{tabular}


Table 2 Summary of published methods based on NPs for the determination of TNT

\begin{tabular}{|c|c|c|c|c|}
\hline Method, applied nanomaterals & Sample & $\mathrm{LOD} / \mu \mathrm{mol} \mathrm{L}-1$ & Linear range/ $\mu \mathrm{mol} \mathrm{L} \mathrm{L}^{-1}$ & Year, Ref \\
\hline Fluorometric, silica NPs & - & 1.0 & - & 2010,30 \\
\hline Fluorometric, Mn dopped ZnS QDs & - & 0.05 & $0.05-1.8$ & 2011,22 \\
\hline Fluorometric,Au@ $\mathrm{SiO}_{2} @ \mathrm{Ag} 15$ mesoflowers & - & $4.4 \times 10^{-4}$ & - & 2012,24 \\
\hline Colorimetric, amine capped AuNPs & - & $4 \times 10^{-6}$ & $(0.004-4) \times 10^{-3}$ & 2012,25 \\
\hline Fluorometric, graphene QDs & - & 2.2 & $2.2-809$ & 2012,26 \\
\hline Fluorometric, MIP-capped CdTe QDs & - & 0.28 & $0.8-30$ & 2013,27 \\
\hline FRET $^{a}$, HQs capped ZnS NPs, & - & 0.01 & $0-1.89$ & 2013,28 \\
\hline Fluorometric, creatinine-CdSe/ZnS QDs & Soil samples & 0.025 & $0.044-1.32$ & 2013,29 \\
\hline $\mathrm{SERS}^{\mathrm{a}}$, graphene nanosheets/AgNPs & Water samples & - & $10^{-5}-10$ & 2013,21 \\
\hline Spectrophotometric, AuNPs & Water samples & 27 & $80-1200$ & 2014,31 \\
\hline Fluorometric, N-rich C-dots & Water samples & 0.001 & $0.01-1.5$ & 2015,32 \\
\hline Our method & Water samples & 0.0022 & $0.007-0.25$ & - \\
\hline
\end{tabular}

a. Abbreviations: QDs, quantum dots; FRET, fluorescent resonance energy transfer; HQs, 8-hydroxyquinoline; SERS, surface-enhanced Raman spectroscopy.

Table 3 Results for the determination of TNT in the samples using the developed method

\begin{tabular}{ccccc}
\hline Sample & $\begin{array}{c}\text { Added/ } \\
\mu \text { mol L }\end{array}$ & $\begin{array}{c}\text { Found } \\
\text { purposed } \\
\text { method }\end{array}$ & \multicolumn{1}{c}{$\begin{array}{c}\text { Recovery, } \\
\%\end{array}$} & $t$-Statistic ${ }^{\mathrm{b}}$ \\
\hline Tap water & 0.20 & $0.195 \pm 0.003$ & $97.30 \pm 1.65$ & 2.91 \\
& 0.50 & $0.508 \pm 0.008$ & $101.70 \pm 1.69$ & 1.74 \\
River water & 0.20 & $0.193 \pm 0.006$ & $96.30 \pm 3.13$ & 2.13 \\
& 0.50 & $0.520 \pm 0.015$ & $103.19 \pm 2.93$ & 1.82 \\
& 1.00 & $1.024 \pm 0.012$ & $102.36 \pm 1.17$ & 3.43 \\
Lake water & 0.20 & $0.207 \pm 0.007$ & $103.30 \pm 3.57$ & 1.55 \\
& 0.50 & $0.491 \pm 0.014$ & $98.25 \pm 2.78$ & 1.11 \\
& 1.00 & $1.008 \pm 0.022$ & $100.83 \pm 2.19$ & 0.65 \\
\hline
\end{tabular}

a. Mean of three determinations \pm standard deviation.

b. $t$-Critical $=3.18$ for $n=3$ and $P=0.05$.

and accurate responses could not be obtained with consistency. This is probably due to active sites on C-dots. However, in our system, the amine groups are on the AuNPs surface, and interference cannot affect the emission intensity of C-dots. Finally, it should be mentioned that C-dots-AuNPs as a novel FRET system may have other potential analytical applications.

On the other hand, the interference effect of some potentially interfering substances were tested. Increasing amounts of these species were added into a standard solution of $50 \mathrm{nmol} \mathrm{L}^{-1}$ TNT. The tolerable concentration ratios for interferences in relative error of $<5 \%$ were over 4000 for $\mathrm{Na}^{+}, \mathrm{K}^{+}, \mathrm{Ca}^{2+}, \mathrm{Mg}^{2+}$, $\mathrm{Cl}^{-}, \mathrm{NO}_{3}^{-}, \mathrm{SO}_{4}^{2-}, \mathrm{PO}_{4}^{3-}, 1000$ for $\mathrm{Zn}^{2+}, \mathrm{Cu}^{2+}, \mathrm{Fe}^{3+}, 500$ for $\mathrm{Pb}^{2+}$, $\mathrm{Hg}^{2+}, \mathrm{As}^{3+}, \mathrm{Mn}^{2+}$, acetone, acetonitrile, and ethanol. As seen, the amounts of most potentially interfering species in water samples are below their tolerable, so there would be no interference from these species in TNT determination.

\section{Analysis of real samples}

The procedure was easily applied to the determination of TNT in spiked environmental water samples. No preliminary step for TNT isolation was needed, just, the sample filtration and suitable dilution were done. Known quantities of TNT were added into the samples before the pretreatment step, and then the samples were analyzed according to the general procedure described in the Experimental section. As shown in Table 3, good recoveries were obtained.

\section{Conclusions}

The carbon nanodots in the presence of EDA-capped AuNPs were successfully used as a fluorescence probe to detect ultratrace amounts of TNT in water samples. AuNPs effectively quench the fluorescence emission of C-dots, due to their mutual interaction and energy transferring from C-dots to AuNPs. TNT has a restoring effect for a quenched system as a result of its interaction with amino groups on the surfaces of AuNPs, and it is the basis for TNT determination. The developed fluorescence probe has good selectivity to TNT and is suitable for its determination in environmental waters.

\section{Supporting Information}

Supporting Information includes absorption spectra of citrate capped-AuNPs in the presence of various concentrations of TNT (Fig. S1) and effect of experimental condition on the fluorescence response of estabilished sensor (Fig. S2). This material is available free of charge on the Web at http://www. jsac.or.jp/analsci/.

\section{References}

1. B. J. Johnson, I. A. Leska, A. Medina, N. F. Dyson, M. Nasir, B. J. Melde, J. R. Taft, and P. T. Charles, Sensors, 2012, 12, 14953.

2. I. U. Mohammadzai, T. Ashiuchi, S. Tsukahara, Y. Okamoto, and T. Fujiwara, J. Chin. Chem. Soc., 2005, 52, 1037.

3. Toxicological Profile for 2,4,6-Trinitrotoluene, US Department of Health and Human Services, Public Health Service, Agency for Toxic Substances and Disease Registry, 1995.

4. Y. H. Lee, H. Liu, J. Y. Lee, S. H. Kim, S. K. Kim, J. L. Sessler, Y. Kim, and J. S. Kim, Chem. Eur. J., 2010, 16, 5895.

5. F. Fant, A. de Sloovere, K. Matthijsen, C. Marle, S. Fantroussi, and W. Verstraete, "Environmental Pollution", 2000, Vol. 111, Elsevier, Oxford, 503.

6. P. Marks, S. Cohen, and M. Levine, J. Polym. Sci., Part A, 2013, 51, 4150.

7. L. Song and J. E. Bartmess, Rapid Commun. Mass 
Spectrom., 2009, 23, 77.

8. Y. Zhang, X. Ma, S. Zhang, C. Yang, Z. Ouyang, and X. Zhang, Analyst, 2009, 134, 176.

9. D. S. Moore and R. J. Scharff, Anal. Bioanal. Chem., 2008, 393, 1571.

10. M. S. Meaney and V. L. McGuffin, Anal. Bioanal. Chem., 2008, 3391, 2557.

11. A. Üzer, E. Erçă̆, and R. Apak, Anal. Chim. Acta, 2005, 534, 307.

12. A. Üzer, E. Erçă̆, and R. Apak, Forensic Sci. Int., 2008, 174,239

13. M. Mäkinen, M. Nousiainen, and M. Sillanpää, Mass Spectrom. Rev., 2011, 30, 940.

14. E. G. Breijoa, C. O. Pinatti, R. M. Peris, M. A. Fillol, R. M. Manez, and J. S. Camino, Sens. Actuators, A, 2013, 192, 1.

15. J. L. Gottfried, F. C. De Lucia Jr, C. A. Munson, and A. W. Miziolek, Anal. Bioanal. Chem., 2009, 395, 283.

16. M. R. Leahy-Hoppa, M. J. Fitch, and R. Osiander, Anal. Bioanal. Chem., 2009, 395, 247.

17. L. C. Pacheco-Londoño, W. Ortiz-Rivera, O. M. PrimeraPedrozo, and S. P. Hernández-Rivera, Anal. Bioanal. Chem., 2009, 395, 323.

18. A. W. Fountain, S. D. Christesen, R. P. Moon, J. A. Guicheteau, and E. D. Emmons, Appl. Spectrosc., 2014, 68, 795.

19. J. S. Caygill, F. Davis, and S. P. J. Higson, Talanta, 2012 , 88, 14.

20. M. S. Meaney and V. L. McGuffin, Anal. Chim. Acta, 2008, 610, 57.

21. M. Liu and W. Chen, Biosens. Bioelectron., 2013, 46, 68.

22. X. Liu, L. Zhao, H. Shen, H. Xu, and L. Lu, Talanta, 2011, 83, 1023.

23. S. S. R. Dasary, A. K. Singh, D. Senapati, H. Yu, and P. C. Ray, J. Am. Chem. Soc., 2009, 131, 13806.

24. A. Mathew, P. R. Sajanlal, and T. Pradeep, Angew. Chem.
Int. Ed., 2012, 51, 9596.

25. D. Lin, H. Liu, K. Qian, X. Zhou, L. Yang, and J. Liu, Anal. Chim. Acta, 2012, 744, 92.

26. L. Fan, Y. Hu, X. Wang, L. Zhang, F. Li, D. Han, Z. Li, Q. Zhang, Z. Wang, and L. Niu, Talanta, 2012, 101, 192.

27. S. Xu, H. Lu, J. Li, X. Song, A. Wang, L. Chen, and S. Han, Appl. Mater. Interfaces, 2013, 5, 8146.

28. L. Feng, C. Wang, Z. Ma, and C. Lü, Dyes Pigm., 2013, 97 , 84.

29. C. Carrillo-Carrión, B. M. Simonet, and M. Valcárcel, Anal. Chim. Acta, 2013, 792, 93.

30. J. Feng, Y. Li, and M. Yang, Sens. Actuators, B, 2010, 145, 438.

31. X. D. Xia and H. W. Huang, Chin. Chem. Lett., 2014, 25, 1271.

32. L. Zhang, Y. Han, J. Zhu, Y. Zhai, and S. Dong, Anal. Chem., 2015, 87, 2033.

33. X. Y. Xu, R. Ray, Y. L. Gu, H. J. Ploehn, L. Gearheart, K. Raker and W. A. Scrivens, J. Am. Chem. Soc., 2004, 126, 12736.

34. S. T. Yang, L. Cao, P. G. Luo, F. Lu, X. Wang, H. F. Wang, M. J. Meziani, Y. F. Liu, G. Qi, and Y. P. Sun, J. Am. Chem. Soc., 2009, 131, 11308.

35. S. N. Baker, and G. A. Baker, Angew. Chem., Int. Ed., 2010, 49, 6726

36. X. Wang, K. Qu, B. Xu, Ji. Ren, and X. Qu, Nano Res., 2011, 4, 908.

37. W. Shi, Q. Wang, Y. Long, Z. Cheng, S. Chen, H. Zheng, and Y. Huang, Chem. Commun., 2011, 47, 6695.

38. W. Xue, Z. Lin, H. Chen, C. Lu, and J. M. Lin, J. Phys. Chem. C, 2011, 115, 21707.

39. M. Amjadi, J. Hassanzadeh, and J. L. Manzoori, Microchim. Acta, 2014, 181, 1851.

40. H. Dai, Y. Shi, Y. Wang, Y. Sun, J. Hu, P. Ni, and Z. Li, Sens. Actuators, B, 2014, 20, 201. 